\title{
The Validity of a Health Education Program in Prevention and Increasing Awareness of Some Prevalent Health Problems among Children at Remote Areas in South Sinai
}

\author{
By Gamal A. Yamamah* \\ Mohab M. Salah \\ Hany Shehatat \\ Ahmed M. Omar ${ }^{+}$ \\ Hasaneen M. Hasanien
}

\begin{abstract}
The objective of this study was to provide simple and applicable health education programs for increasing awareness about goiter and decreasing rates of skin diseases among South Sinai children. Ras Sidre district was selected for this prospective cohort study. 731 school children were recruited for the study. The study was mediated through three consecutive phases: the first included dermatologic examination for 15 skin diseases and primary screening for awareness about goiter through a simple comprehensive questionnaire. In the second phase, we applied a health education program in the form of fliers and presentations. During the third phase, we evaluated the efficacy of a health education program through detailed dermatologic examination for the studied skin diseases and rescreening of awareness about goiter through our simple questionnaire after one year of providing education program. Results showed that awareness about goiter regarding iodine function, iodine deficiency manifestations, goiter prevention and goiter management increased significantly $(p<0.001)$ in all school grades. However, children of urban origin showed higher levels of awareness compared to Bedouins. Dermatologic examination before the education program showed that the prevalent diseases were seborrheic dermatitis (60.07\%), pitriasis alba $(37.77 \%)$, pediculosis $(25.18 \%)$ and xerosis $(19.96 \%)$. Education program caused highly significant decrease in prevalence of pediculosis, fungal infections, seborrheic dermatitis and scabies $(p<0.001)$. Significant decrease was also noticed for impetigo $(p=0.01)$. Our simple health education program provided in a presentable way by physicians proved to be effective in decreasing rates of some skin diseases and increasing awareness about goiter, which are prevalent health problems in South Sinai. Such provided programs will help in decreasing school absence days, as well as decreasing medical advice and therapy costs for family and health authorities.
\end{abstract}

Keywords: Awareness, Health education, Goiter, Iodine Deficiency Disorders (IDD), Skin diseases, South Sinai

\section{Introduction}

Inhabitants of South Sinai (S.Sinai) have unique characteristics that are different from Egyptians living in other governorates (SEAM 2004). The area lies in a hyper arid zone (Danin 1983). The sun rises most days of the year (350 days) and is shining for most daytime hours (SEAM 2004). More than half of S.Sinai

\footnotetext{
"Professor of Pediatrics, Pediatrics Department, National Research Centre, Egypt.

"Researcher of Pediatrics, Pediatrics Department, National Research Centre, Egypt.

${ }^{*}$ Researcher of Dermatology, Skin and Venereal Department, National Research Centre, Egypt.

${ }^{+}$Researcher of Dermatology, Skin and Venereal Department, National Research Centre, Egypt.

-Assistant Researcher of Pediatrics, Pediatrics Department, National Research Centre, Egypt.
} 
inhabitants descend from Bedouin tribes. Water resources in S.Sinai are potentially limited (Iwaco Egypt 2003).

Skin morbidities have been observed to be higher in desert areas than in nondesert areas (Griffiths et al. 2004). Many skin disorders, such as photosensitivity, predominate in sunny areas as they are caused by ultraviolet B and A rays (Hawk et al. 2004).

Many skin diseases proved to be highly prevalent among S.Sinai children. A previous study showed that $71.4 \%$ of children had one or more skin diseases. The most prevalent diseases were pediculosis and pityriasis alba (Yamamah et al. 2012).

Thyroid hormones need iodine as an essential trace element for their synthesis, which is essential for normal human growth and development. The principal source of iodine for humans is food. A diet rich in iodine content often comes from fish and sea foods (Hetzel 1989). Iodine deficiency in children leads to goiter and serious effects on physical and mental development (WHO-UNICEFICCIDD 2003).

Thyroid volume reference was adopted in 1997 (WHO/ICCIDD 1997). Sexspecific upper normal limits of thyroid volume (the 97 th percentile) were provided based on age and body surface area (Zimmermann et al. 2004).

Prevention and control of iodine deficiency disorders (IDD) can be easily achieved through appropriate iodine supplementation (Jukić et al. 2008). Salt iodination is most frequently used for iodine prophylaxis (Hetzel 1989). Salt iodization is well established in Egypt since 1994. Endemic goiter and low urinary iodine concentration have been reported in several regions in Egypt (El Sayed et al. 1995, Yamamah and Hassanien 1997, Mansour et al. 2001). Goiter prevalence in S.Sinai using current WHO/ICCIDD recommended cutoff values was estimated to be $13.6 \%$ (15.1\% for males and $12.4 \%$ for females). The highest distribution of goiter was recorded at $20.0 \%$ in Ras Sidre (Yamamah et al. 2013).

The World Health Organization recommended health education as an essential tool to achieve the goal "health for all in the year 2010". It is accepted that health education should be compulsory in schools. As practice and training brings maximum results, the most suitable place to teach health education is the school (Rajapkse 2008).

The main purpose of health education is to offer people and local communities the information, resources and solutions they need to make healthier lifestyle decisions. The effectiveness of this education is ultimately measured by its ability to reduce morbidity and mortality of the disease; cohort studies are frequently used to evaluate screening (LaMorte 2016).

\section{Objectives}

We aimed to provide a simple and applicable health education program and evaluate its efficacy for increasing awareness about goiter and decreasing rates of skin diseases among S.Sinai children. 


\section{Subjects and Methods}

- Study design: Prospective cohort study.

- Study site: Ras Sidre district was selected as it has the highest prevalence of goiter accounting for 20.0\% (Yamamah et al. 2013). It also has the highest rates of skin diseases among S.Sinai children (Yamamah et al. 2012).

- Sample size: 731 school children, representing $20.57 \%$ of all registered children in the studied area (Abdelkader 2005), were subjected to a health education program about goiter and prevalent skin diseases.

- Subject (children): Seven schools were selected randomly at Ras Sidre educational district. 731 children were enrolled in the study representing all present population variations regarding age (6-18 years), gender (male and female), geographic distribution (living at city, villages, Bedouin settlements) and ethnic origin (Bedouin and urban). Cases were attendants of schools (primary, prep, and secondary schools).

- Exclusion criteria: Cases that travel away of S.Sinai more than 4 months per year.

- The study was mediated after obtaining approval from the Ethical Committee of the National Research Centre (registration number 13-138). Written informed consent was obtained from parents after full discussion about the aim of the study.

\section{Methods}

The following was done for all subjects of the study:

\section{- Phase I:}

a) Collecting personal and medical history from the child or their parent including birth date and ethnic origin (Bedouin or urban).

b) Thorough clinical examination by pediatrician.

c) Detailed dermatologic examination for 15 diseases assessing presence of each disease, distribution and severity for 556 children by dermatologist.

d) Screening of awareness about goiter through simple questionnaire including 4 items: iodine function, iodine deficiency manifestations, goiter prevention and goiter management for 731 children (see Questionnaire).

e) Data were recorded and tabulated.

A similar questionnaire was used by Kim et al. (2014) in the survey mediated for school students in the Phillippines. The simple questionnaire (consisting of five main questions and two sub-questions) was answered by the study subjects. The questions included such inquiries as: (1) Have you heard about the problems associated with iodine deficiency (ID) and insufficient intake of iodine in the human body?; (2) Can you list some problems resulting from ID?; (2-1) Which problems? (Select all you can list); (3) Where do you receive information about IDD and preventing them?; (4) What do you need to do about ID?; (5) Do you buy iodized salt? 
- Phase II: The aim was to provide a health education program through:

a) Fliers: We prepared 5 different fliers regarding the required educational knowledge needed for the designed program of health education. Two were designed for thyroid and goiter. Three were prepared for dermatologic diseases regarding the most commonly discovered diseases including pediculosis, scabies, warts, xerosis, pitriasis alba, acne vulgaris and seborrheic dermatitis (Annexes I-V).

$\checkmark$ Flier I: Goiter, iodine deficiency and dietary sources of iodine. (Annex I)

$\checkmark$ Flier II: How to expect goiter, prevention and treatment. (Annex II)

$\checkmark$ Flier III: Pediculosis and scabies. Mode if infection, clinical presentation, prevention and treatment. (Annex III)

$\checkmark$ Flier IV: Seborrheic dermatitis, Warts and xerosis. Mode of infection, clinical presentation, prevention and treatment. (Annex IV)

$\checkmark$ Flier V: Pitriasis alba and acne vulgaris, etiology, clinical presentation, prevention and treatment. (Annex V)

During the field visits, fliers were distributed to children and teachers. Simple explanation about the diseases was provided according to the age of the children. Discussion about each disease regarding manifestations and prevention was mediated.

Lowe et al. (2015) included a distribution of leaflets and posters designed by the research team in their own research. These were written in Urdu, and they outlined the consequences of iodine deficiency and promoted the use of iodized salt. These were distributed at the local health centers and schools in Pakistan in order to raise awareness.

b) We prepared three presentations that communicated the required educational knowledge for the designed program of health education. One was designed for thyroid and goiter. Two were prepared concerning dermatologic diseases, including the most prevalent diseases such as pediculosis, scabies, warts, xerosis, pitriasis alba, acne vulgaris, seborrheic dermatitis, photosensitivity, eczyma, urticaria, fungal infections, impetigo, psoriasis and vitelligo. Data were presented through data show and followed by open discussion. Simple explanation about each disease was provided according to the age of the children. Colored pictures and videos were provided for demonstration. Discussion about each disease regarding manifestations and prevention was mediated. Children were allowed to participate in the discussion and were asked about their understanding of the mission of the applied program.

Phase I and Phase II were conduted during October and November 2013. 
- Phase III: This phase focused on the evaluation of the health education program's efficacy through:

$\checkmark$ Detailed dermatological examination assessing the presence of diseases, as well as their distribution and severity

$\checkmark$ Rescreening of awareness about goiter through our simple questionnaire

Phase III was conducted during October and November 2014 as the school year begins in September. Data were tabulated and analyzed statistically using SPSS Version 14.0 (SPSS, Inc., Chicago, IL, USA). Data were expressed as numbers (n) and percentages. Pearson's chi squared test was used in the analysis of results. A p-value of $<0.05$ was considered to indicate statistical significance.

\section{Results}

Table 1. Skin Diseases Prevalent Among Children at Ras Sidre before Education Program Implementation

\begin{tabular}{|c|c|c|c|c|c|}
\hline \multirow[b]{2}{*}{ No } & \multirow[b]{2}{*}{ Skin disease } & \multicolumn{4}{|c|}{ Number of cases at different school grades } \\
\hline & & $\begin{array}{c}\text { Primary schools } \\
(\mathrm{n}=336) \\
\text { number }(\%)\end{array}$ & $\begin{array}{c}\text { Preparatory } \\
(n=175) \\
\text { number }(\%)\end{array}$ & $\begin{array}{c}\text { Secondary } \\
(n=45) \\
\text { number }(\%)\end{array}$ & $\begin{array}{c}\text { Total } \\
(\mathrm{n}=556) \\
\text { number }(\%)\end{array}$ \\
\hline 1 & Pediculosis & $130(38.69 \%)$ & $9(5.14 \%)$ & $1(2.22 \%)$ & $140(25.18 \%)$ \\
\hline 2 & Seb. dermatitis & $142(42.26 \%)$ & $155(88.57 \%)$ & $37(82.22 \%)$ & $334(60.07 \%)$ \\
\hline 3 & Photosensitivity & $22(6.55 \%)$ & $16(9.14 \%)$ & $3(6.67 \%)$ & $41(7.37 \%)$ \\
\hline 4 & Acne vulgaris & $14(4.17 \%)$ & $36(20.57 \%)$ & $28(62.22)$ & $78(14.03 \%)$ \\
\hline 5 & Pitriasis alba & $161(47.92 \%)$ & $42(24.0 \%)$ & $7(15.56 \%)$ & $210(37.77 \%)$ \\
\hline 6 & Eczyma & $26(7.74 \%)$ & $17(9.71 \%)$ & $9(20.0 \%)$ & $52(9.35 \%)$ \\
\hline 7 & Xerosis & $82(24.40 \%)$ & $19(10.86 \%)$ & $10(22.22 \%)$ & $111(19.96 \%)$ \\
\hline 8 & Urticaria & $29(8.63 \%)$ & $8(4.57 \%)$ & $1(2.22 \%)$ & $38(6.83 \%)$ \\
\hline 9 & Warts & $21(6.25 \%)$ & $7(4.0 \%)$ & $0(0.0 \%)$ & $28(5.04 \%)$ \\
\hline 10 & Fungal infection & $11(3.27 \%)$ & $16(9.14 \%)$ & $8(17.78 \%)$ & $35(6.39 \%)$ \\
\hline 11 & Impetigo & $15(4.46 \%)$ & $20(11.43 \%)$ & $0(0.0 \%)$ & $35(6.29 \%)$ \\
\hline 12 & Freckles & $3(0.89 \%)$ & $5(2.86 \%)$ & $0(0.0 \%)$ & $6(1.08 \%)$ \\
\hline 13 & Scabies & $12(3.57 \%)$ & $1(0.57 \%)$ & $0(0.0 \%)$ & $13(2.34 \%)$ \\
\hline 14 & Vitelligo & $12(3.57 \%)$ & $3(1.71 \%)$ & $0(0.0 \%)$ & $5(0.90 \%)$ \\
\hline 15 & Psoriasis & $0(0.0 \%)$ & $0(0.0 \%)$ & $0(0.0 \%)$ & $0(0.0 \%)$ \\
\hline
\end{tabular}

Source: Authors' estimations.

Table 1 shows the prevalent skin diseases before the education program among children under study in different school grades. Seborheic dermatitis was the most prevalent $(60.07 \%)$; pitriasis alba was the next $(37.77 \%)$. Other skin diseases were also present, such as pediculosis (25.18\%) and xerosis (19.96\%). The prevalence of many diseases differs according to school grade. PRA is more prevalent in primary school children (47.92\%) compared to prep and secondary school children ( 24.0 and $15.56 \%$ respectively).

Table 2 and Figure 1 illustrate the efficacy of the health education program regarding skin diseases of studied children. High significant positive effects were reported $(\mathrm{p}<0.001)$. Pediculosis, Seborrheic dermatitis, fungal infections and 
scabies prevalence decreased to $1.74 \%, 6.18 \%, 1.18 \%$ and $2.35 \%$ respectively. The responses were slightly related to age as shown in Table 2 and Figure 1.

Table 2. Effect of Health Education Program on Prevalence of Skin Diseases in Ras Sidre at Different School Grades

\begin{tabular}{|c|l|c|c|c|c|c|c|c|c|}
\hline \multirow{2}{*}{ No } & \multirow{2}{*}{ Skin disease } & \multicolumn{2}{|c|}{$\begin{array}{c}\text { Primary } \\
\text { Schools }\end{array}$} & \multicolumn{2}{|c|}{ Preparatory } & \multicolumn{2}{|c|}{ Secondary } & \multicolumn{2}{|c|}{ Total } \\
\cline { 3 - 10 } & & $\mathbf{\%}$ & p-value & \% & p-value & \% & p-value & $\%$ & p-value \\
\hline $\mathbf{1}$ & Pediculosis & 2.43 & $<0.001$ & 0.0 & NS & 0.0 & NS & 1.47 & $<0.001$ \\
\hline $\mathbf{2}$ & Seb. dermatitis & 3.4 & $<0.001$ & 5.38 & $<0.001$ & 21.95 & $<0.001$ & 6.18 & $<0.001$ \\
\hline $\mathbf{3}$ & Photosensitivity & 7.28 & NS & 7.53 & NS & 7.32 & NS & 7.35 & NS \\
\hline $\mathbf{4}$ & Acne vulgaris & 6.8 & NS & 28.42 & NS & 60.98 & NS & 19.41 & 0.03 \\
\hline $\mathbf{5}$ & Pitriasis RP & 43.69 & NS & 24.73 & NS & 2.44 & 0.03 & 33.53 & NS \\
\hline $\mathbf{6}$ & Eczema & 15.05 & $<0.01$ & 6.45 & NS & 9.96 & NS & 12.06 & NS \\
\hline $\mathbf{7}$ & Xerosis & 23.79 & NS & 10.75 & NS & 17.07 & NS & 19.41 & NS \\
\hline $\mathbf{8}$ & Urticaria & 7.77 & NS & 5.38 & NS & 2.44 & NS & 6.47 & NS \\
\hline $\mathbf{9}$ & Warts & 2.91 & NS & 2.15 & NS & 4.88 & NS & 2.94 & NS \\
\hline $\mathbf{1 0}$ & Fungal infection & 0.97 & NS & 1.08 & $<0.01$ & 2.44 & 0.02 & 1.18 & $<0.001$ \\
\hline $\mathbf{1 1}$ & Impetigo & 3.4 & NS & 1.08 & $<0.01$ & 0.0 & NS & 2.35 & $<0.01$ \\
\hline $\mathbf{1 3}$ & Scabies & 0.005 & 0.02 & 0.0 & NS & 0.0 & NS & 0.29 & $<0.001$ \\
\hline $\mathbf{1 4}$ & Vetilligo & 0.97 & NS & 1.08 & NS & 0.0 & NS & 0.88 & NS \\
\hline
\end{tabular}

Note: NS means Non Significant.

Source: Authors' estimations.

Figure 1. Effect of Health Education Program on \% Prevalence of Skin Diseases

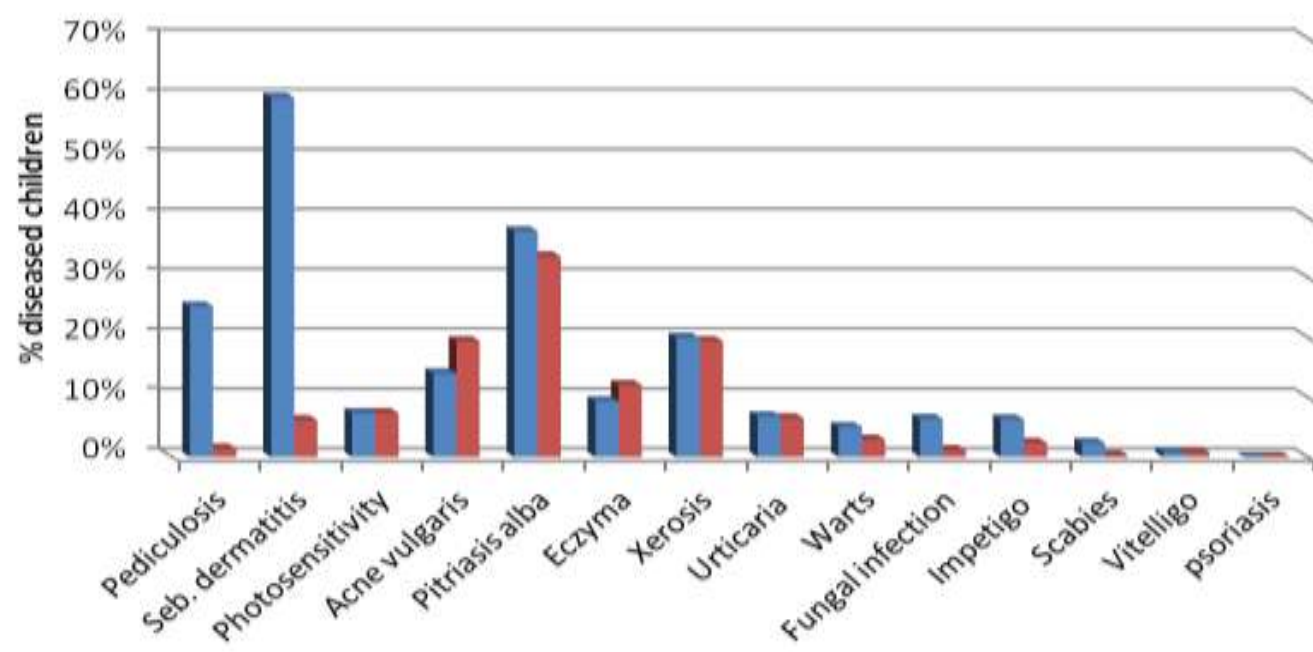

Examined skin diseases

Before education

after education

Source: Authors' estimations.

Table 3 illustrates the efficacy of the health education program regarding increase of awareness about goiter in all grades of school children at Ras Sidre. General awareness levels before implementation of the health education program were only $21.1 \%, 22.9 \%$ and $54.4 \%$ for primary, prep and secondary school children, respectively. Our educational program raised awareness to higher levels 
for primary school children (81.95-85.34\%), for prep school children (84.3$90.58 \%$ ) and for secondary school children (83.6-95.04\%). High significant positive effects regarding the four items of evaluation for goiter awareness were reported $(p<0.001)$. Figures $2 a, 2 b \& 2 c$ illustrate the effect of awareness increases in primary, prep and secondary schools respectively.

Table 3. Awareness Effect of Health Education Program at Different School Grades

\begin{tabular}{|c|c|c|c|c|c|c|c|c|c|}
\hline \multirow{2}{*}{ Item tested } & \multicolumn{3}{|c|}{ Primary schools $(n=266)$} & \multicolumn{3}{|c|}{ Prep $(n=223)$} & \multicolumn{3}{|c|}{$2 r y(n=242)$} \\
\hline & before & after & p-value & before & after & p-value & before & after & p-value \\
\hline $\begin{array}{c}\text { Iodine function } \\
\text { Number } \%\end{array}$ & $\begin{array}{c}56 \\
21.1\end{array}$ & $\begin{array}{c}244 \\
84.21\end{array}$ & $<0.001$ & $\begin{array}{c}51 \\
22.9\end{array}$ & $\begin{array}{l}188 \\
84.3\end{array}$ & $<0.001$ & $\begin{array}{l}110 \\
45.4\end{array}$ & $\begin{array}{l}201 \\
83.6\end{array}$ & $<0.001$ \\
\hline $\begin{array}{c}\text { ID manifestations } \\
\text { Number } \%\end{array}$ & $\begin{array}{c}56 \\
21.1\end{array}$ & $\begin{array}{c}218 \\
81.95\end{array}$ & $<0.001$ & $\begin{array}{c}51 \\
22.9\end{array}$ & $\begin{array}{c}197 \\
88.34\end{array}$ & $<0.001$ & $\begin{array}{l}110 \\
45.4\end{array}$ & $\begin{array}{c}230 \\
95.04\end{array}$ & $<0.001$ \\
\hline $\begin{array}{l}\text { Goiter prevention } \\
\text { Number } \%\end{array}$ & $\begin{array}{c}56 \\
21.1\end{array}$ & $\begin{array}{c}227 \\
85.34\end{array}$ & $<0.001$ & $\begin{array}{c}51 \\
22.9\end{array}$ & $\begin{array}{c}202 \\
90.58\end{array}$ & $<0.001$ & $\begin{array}{l}110 \\
45.4\end{array}$ & $\begin{array}{c}213 \\
88.02\end{array}$ & $<0.001$ \\
\hline $\begin{array}{l}\text { Goiter treatment } \\
\text { Number } \%\end{array}$ & $\begin{array}{c}56 \\
21.1\end{array}$ & $\begin{array}{c}219 \\
82.33\end{array}$ & $<0.001$ & $\begin{array}{c}51 \\
22.9\end{array}$ & $\begin{array}{l}192 \\
86.9\end{array}$ & $<0.001$ & $\begin{array}{l}110 \\
45.4\end{array}$ & $\begin{array}{c}215 \\
88.84\end{array}$ & $<0.001$ \\
\hline
\end{tabular}

Note: p-value comparing before education versus after, CHI-square.

Source: Authors' estimations.

Figure 2a. Effect of Health Education Program on \% Goiter Awareness in Primary Schools

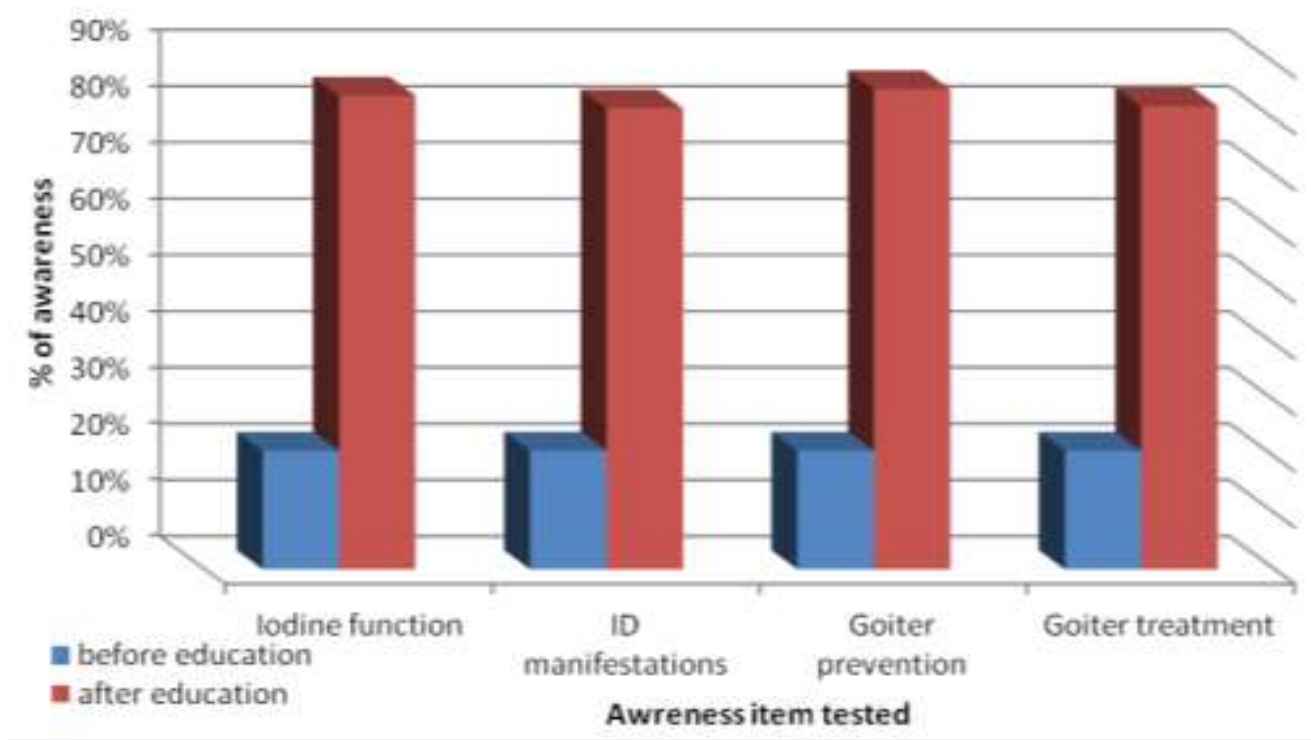

Source: Authors' estimations. 
Figure 2b. Effect of Health Education Program on \% Goiter Awareness in Prep Schools

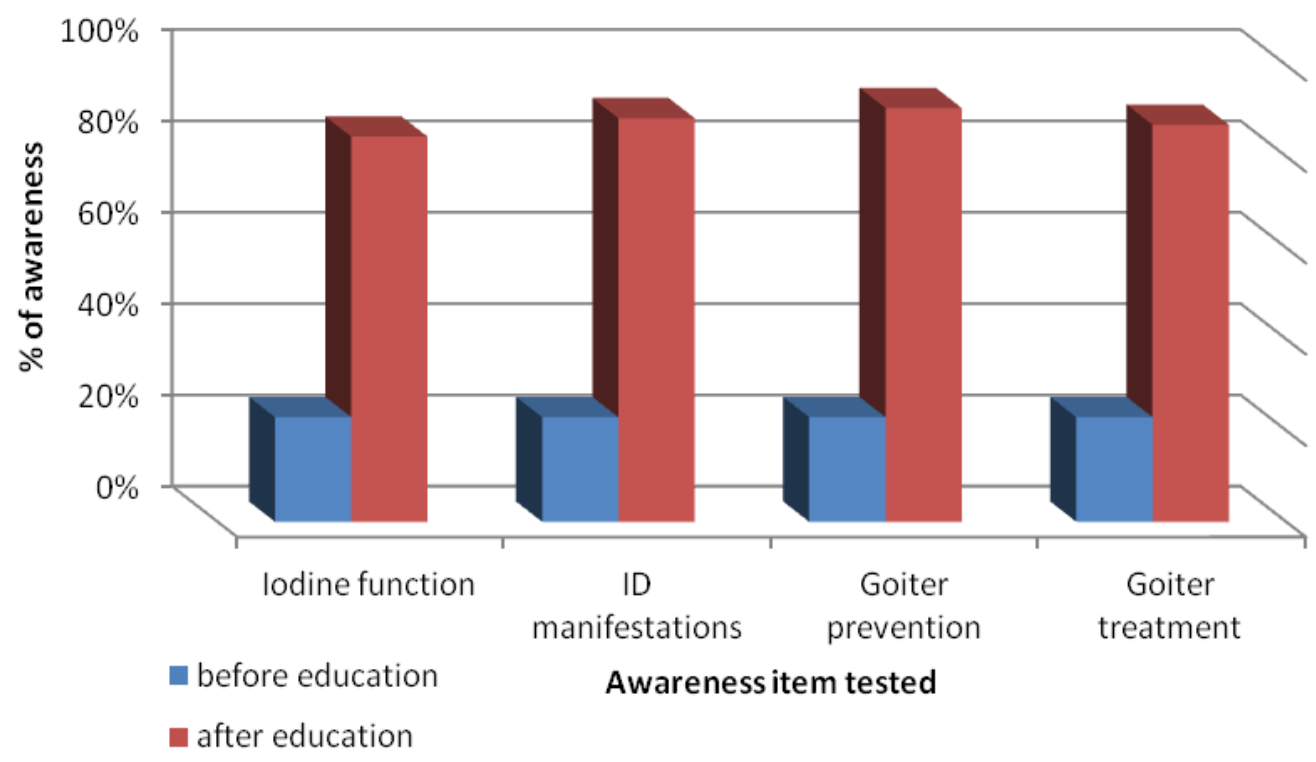

Source: Authors' estimations.

Figure 2c. Effect of Health Education Program on \% Goiter Awareness in 2ry Schools

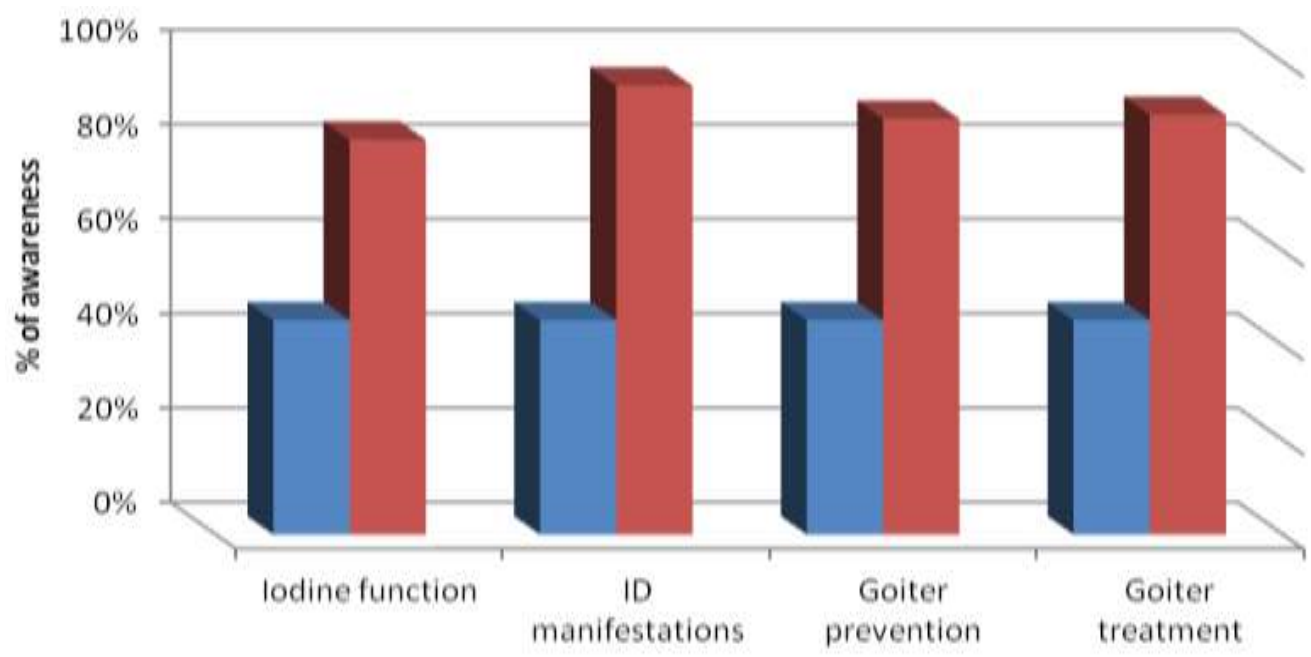

in before...

in after education

Awarenessitemtested

Source: Authors' estimations.

Table 4 and Figures $3 a \& 3 b$ illustrate a higher efficacy of the health education program among children of urban origin compared to Bedouins in primary and prep schools. Awareness levels rose among Bedouins from 55.07\% to $68.12 \%$ in primary schools and from $64 \%$ to $78 \%$ in prep schools. Meanwhile, awareness levels rose at higher levels among urban children, from $89.85 \%$ to $95.94 \%$ in primary schools and from $87.28 \%$ to $98.27 \%$ in prep schools. 
Table 4. Effect of Health Education Program on Awareness for Different Ethnic Groups in South Sinai Primary and Prep School Children

\begin{tabular}{|c|c|c|c|c|c|c|}
\hline \multirow{2}{*}{ Item tested } & \multicolumn{2}{|c|}{ Primary schools (n=266) } & \multicolumn{3}{c|}{ Prep (n=223) } \\
\cline { 2 - 7 } & $\begin{array}{c}\text { Bedouin } \\
(\mathbf{n = 6 9 )}\end{array}$ & $\begin{array}{c}\text { Urban } \\
(\mathbf{n = 1 9 7})\end{array}$ & $\mathbf{p - v a l u e}$ & $\begin{array}{c}\text { Bedouin } \\
(\mathbf{n = 5 0})\end{array}$ & $\begin{array}{c}\text { Urban } \\
(\mathbf{n = 1 7 3})\end{array}$ & p-value \\
\hline $\begin{array}{c}\text { Iodine function } \\
\text { Number \% }\end{array}$ & $\begin{array}{c}47 \\
68.12 \%\end{array}$ & $\begin{array}{c}177 \\
89.85 \%\end{array}$ & $<0.001$ & $\begin{array}{c}37 \\
74 \%\end{array}$ & $\begin{array}{c}151 \\
87.28 \%\end{array}$ & 0.02 \\
\hline $\begin{array}{c}\text { ID manifestations } \\
\text { Number \% }\end{array}$ & 41 & 177 & $<0.001$ & 39 & 158 & 0.011 \\
\hline $\begin{array}{c}\text { Goiter prevention } \\
\text { Number \% }\end{array}$ & $\begin{array}{c}39.42 \% \\
85.07 \%\end{array}$ & $\begin{array}{c}189 \% \\
78.85 \%\end{array}$ & $<0.001$ & $\begin{array}{c}32 \\
64 \%\end{array}$ & $\begin{array}{c}170 \\
98.27 \%\end{array}$ & $<0.001$ \\
\hline $\begin{array}{c}\text { Goiter treatment } \\
\text { Number \% }\end{array}$ & 40 & 179 & $<0.001$ & $\begin{array}{c}34 \\
68 \%\end{array}$ & $\begin{array}{c}158 \\
91.33 \%\end{array}$ & $<0.001$ \\
\hline
\end{tabular}

Note: p-value comparing Bedouin education effect versus urban children, CHI-square.

Source: Authors' estimations.

Figure 3a. Difference of Health Education Program Effect on Awareness for Different Ethnic Groups in South Sinai Primary Schools

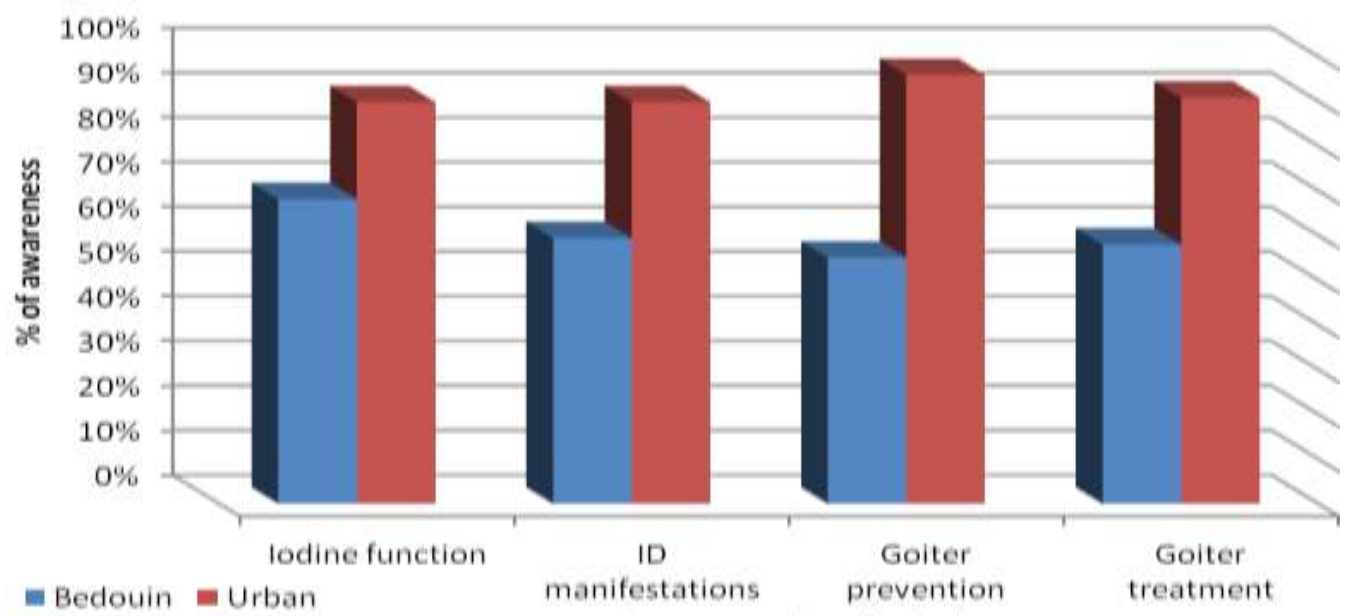

Source: Authors' estimations.

Awareness item tested

Figure 3b. Difference of Health Education Program Effect on Awareness for Different Ethnic Groups in South Sinai Prep Schools

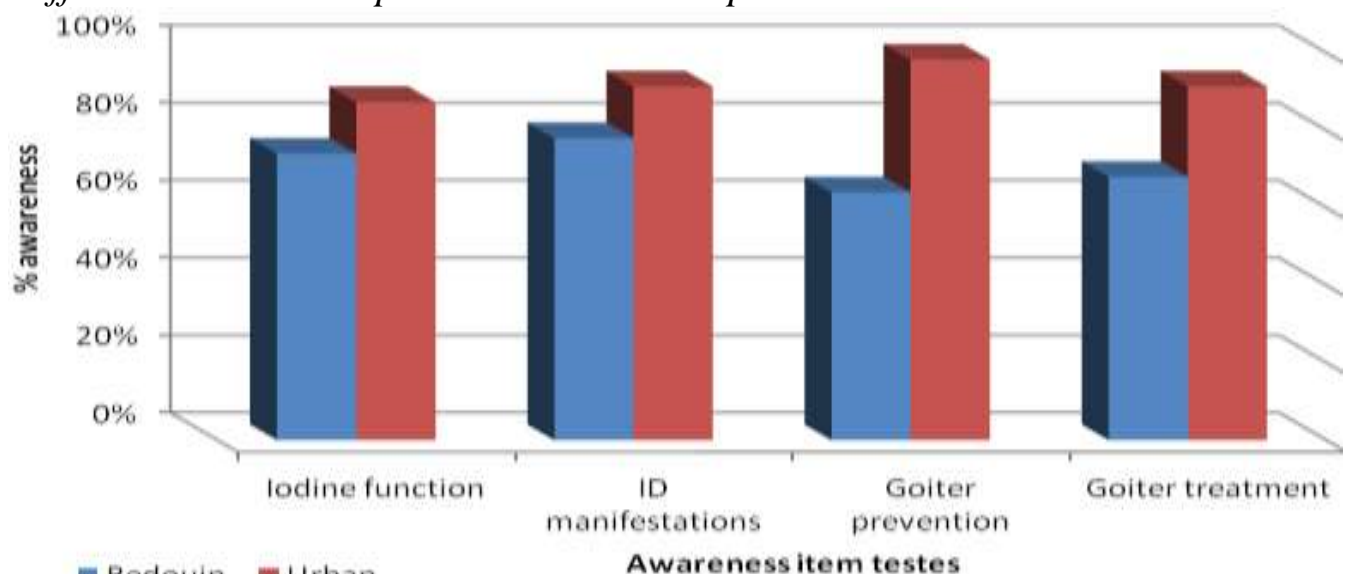

Source: Authors' estimations. 
Table 5 illustrates that the efficacy of the health education program is nearly equal for children at primary, prep and secondary schools at Ras Sidre ( $>0.05)$.

Table 5. Difference of Health Education Program Effect on Awareness Among South Sinai School Children at Different Grades

\begin{tabular}{|l|c|c|c|c|c|c|}
\hline Item tested & $\begin{array}{c}\text { Primary schools } \\
\mathbf{n = 2 6 6}(+/-)\end{array}$ & $\mathbf{p}$ & $\begin{array}{c}\text { Prep schools } \\
\mathbf{n = 2 2 3}(+/-)\end{array}$ & $\mathbf{p}^{*}$ & $\begin{array}{c}\text { Secondary schools } \\
\mathbf{n = 2 4 2}(+/-)\end{array}$ & $\mathbf{p}^{* *}$ \\
\hline Iodine function & $224 / 42$ & 1.0 & $188 / 35$ & 0.21 & $201 / 41$ & 0.21 \\
\hline ID manifestations & $218 / 48$ & 0.23 & $197 / 26$ & 0.08 & $230 / 12$ & 0.004 \\
\hline Goiter prevention & $227 / 39$ & 0.19 & $202 / 21$ & 0.49 & $213 / 29$ & 0.54 \\
\hline Goiter treatment & $219 / 47$ & 0.33 & $192 / 31$ & 0.66 & $215 / 27$ & 0.16 \\
\hline
\end{tabular}

Note: $\mathrm{p}$-value comparing education effect in different school grades, CHI-square.

$\mathrm{p}$ (primary\#prep), $\mathrm{p}^{*}$ (prep\#secondary), $\mathrm{p}^{* *}$ (primary\#secondary).

Source: Authors' estimations.

\section{Discussion}

South Sinai was selected for the present work as it has the highest prevalence of goiter in Egypt (Yamamah et al. 2013) and many skin diseases were also reported to be prevalent (Yamamah et al. 2012). Within S.Sinai, children of Ras Sidre were reported to have the highest prevalence of both groups of diseases. Many environmental and nutritional factors predispose people to skin diseases in the studied area, including arid weather, lack of adequate water and increased solar rays (SEAM 2004).

Our results illustrated the efficacy of health education programs regarding many skin diseases in studied children. Significant decreases were recorded for the prevalence of pediculosis, Seborrheic dermatitis, fungal infections and scabies $(p<0.001)$, as well as for impetigo $(p<0.01)$. The results clearly illustrate the positive effects of the provided health education program by the percentage decrease in infectious skin diseases. For example, Seborrheic dermatitis was prevalent among $60.07 \%$ of examined children prior to the education program. The prevalence decreased to $6.18 \%$ after the program application. Ohkubo et al. (2013) stated that one of the main initial outcome indicators that guarantees usefulness of knowledge dissemination is the degree of awareness that can be measured as a number/percentage of intended users who intend to use the information and knowledge gained. Marked decrease in prevalence of infectious skin diseases confirms the validity of applied health education program.

However, other skin diseases as photosensitivity, xerosis and urticaria showed no significant response. It is possible that increased hygienic measures after applying our program yielded a rapid response regarding infectious agents, such as pediculosis, fungal infections and scabies. On the other hand, non-infectious diseases need a longer time to respond. In addition, environmental factors interacting with non-infectious skin diseases require social and behavioral modifications, which should be considered for future programs.

The results showed that awareness about goiter regarding iodine function, ID manifestations, goiter prevention and goiter management increased significantly $(\mathrm{p}<0.001)$ in all school grades. 
The degree of awareness before the education program was $21.1 \%, 22.9 \%$ and $45.4 \%$ for primary, prep, and secondary school children respectively. The presence of a higher basic level of awareness among secondary school children is logical as they get information out of science and biology studies at schools. The education program lead to rise of awareness for primary, prep and secondary school children to levels reaching $81.95 \%-85.34 \%, 84.3 \%-90.58 \%$ and $83.6 \%$ $95.04 \%$, respectively.

Awareness is the first stage of outcomes that occur when a person recognizes the existence and utility of the knowledge and is aware of the necessary skills and tools that help effective adoption of the knowledge (Ohkubo et al. 2013).

Raising awareness about goiter and IDD was mediated in many countries as it is an important tool for combating this problem. Lowe et al. (2015) highlighted the positive impact of education and awareness raising on iodized salt consumption in a hard to reach, marginalized community in Pakistan. During the intervention, sales of iodized salt increased by $45 \%$.

We used a simplified questionnaire in our study. A similar questionnaire was used by Kim et al. (2014) in the survey mediated for high school students in the Philippines. The majority of students $(70.5 \%)$ were unable to identify problems other than goiter. The questionnaire consisted of five main questions and two sub questions answered by the study subjects. $56.8 \%$ of the students answered for the first question that they have heard about the problems associated with ID. Although $62.3 \%$ of students answered that they can list some other problems resulting from ID, $70.5 \%$ chose goiter as the only problem. $47.9 \%$ of students received information about IDD from school (Kim et al. 2014). The students from the Philippines showed a low degree of awareness comparable to our results prior to education program implementation.

In India, a community-based survey was performed for school-age children (6-12 years) and their mothers in selected tribal mountainous blocks. Knowledge regarding IDD and awareness of iodized salt was assessed. Over $80 \%$ of respondents did not have knowledge of IDD. Study results showed poor community knowledge of iodine nutrition (Bulliyya et al. 2008).

A similar study in Turkey was conducted to determine the prevalence of iodized salt use in the Trabzon region, and the effect of a local mass-media education program in increasing usage. Prior to the intervention, the prevalence of iodized salt consumption was $54.5 \%$. Following the education program, it increased to $62.4 \%$. There was a significant difference in the pre- and postintervention findings $(p=0.00237)$ (Can et al. 2001). Our education program showed slightly higher response effects than that of the Turkish study.

Preset data illustrated higher efficacy of the health education program among children of urban origin compared to Bedouins. Education degrees of parents were much higher among children of urban origin, which explains this discrepancy in the response to the education program. The results declared that the message of health education was received in a more clear way for children of urban origin. The lower increase in awareness among Bedouins denotes that the education program needs to be modified for Bedouins, regarding the expressions provided and models for explanation of provided knowledge. 


\section{Conclusion}

1. Applied health education program was successful for infectious skin diseases with significant decrease of infection rates.

2. Awareness about goiter showed high significant improvement at all school grades. Urban children have higher rate of awareness compared to Bedouins.

3. The provided message needs to be modified for non infectious skin diseases and for Bedouins to get optimum response before applying at other areas. 


\section{Questionnaire}

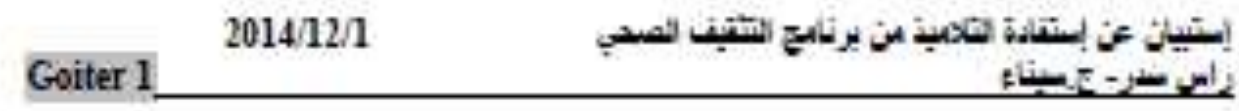

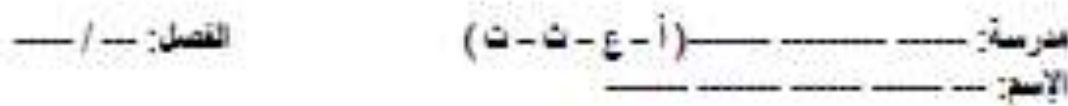

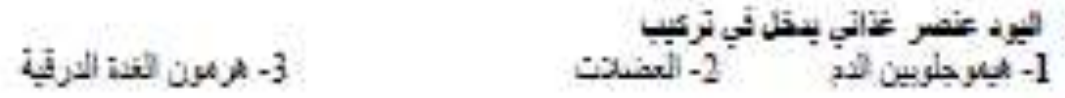

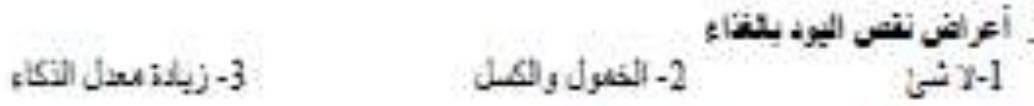

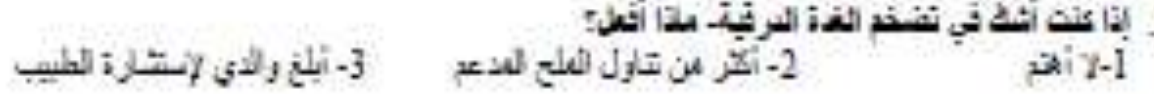

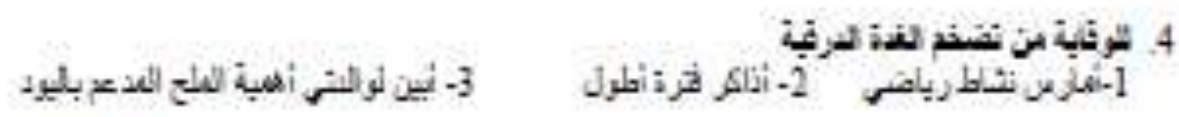

\section{[Euglish translation]}

Measuring degree of goiter awareness questionnaire

Ras Sidre school children-S.Sinai

\section{Before/after bealth edacation}

School:

Child name:

Class:

Date:

1. Iodine is a rutritionsl element is a couponent of:

1- blood hemoglobin 2-muscles 3-thyroid gland hormone

2. Effects of nutritional iodine deficiency.
1. no effect
2- decrease activities
3-increase intelligence

3. What should I do when suspecting enlargement of thyroid gland?
1. don't care
2- increase ioçized salt intake 3- tell parents for doctor
consultation

4. How to prevent enlargement of thyroid gland?
1. do sparts
2-study for longer periods
3- explain the value of iodized salts.


Annex I. Goiter - Iodine deficiency and dietary sources of iodine

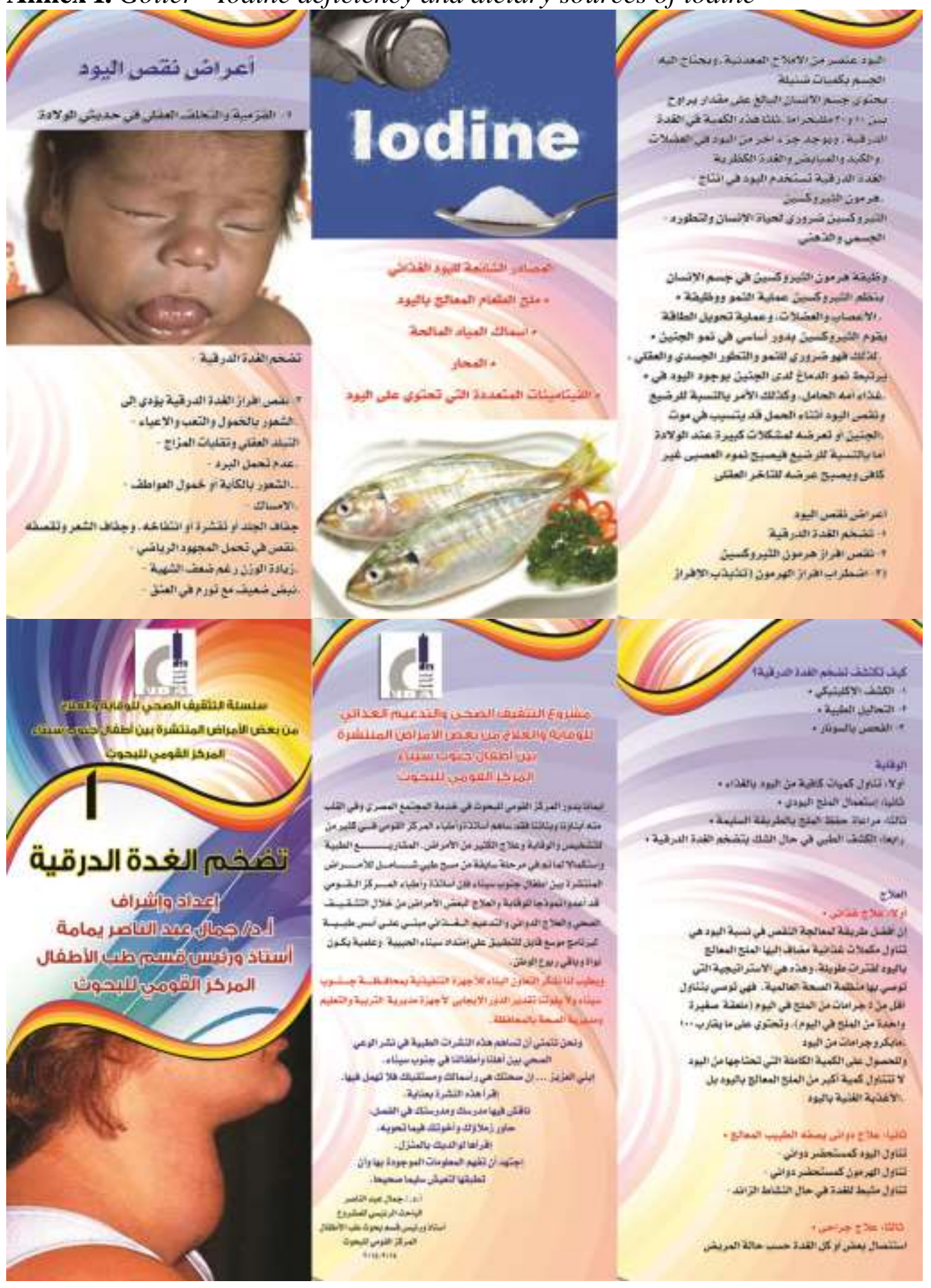


Annex II. Goiter - How to expect goiter, prevention and treatment

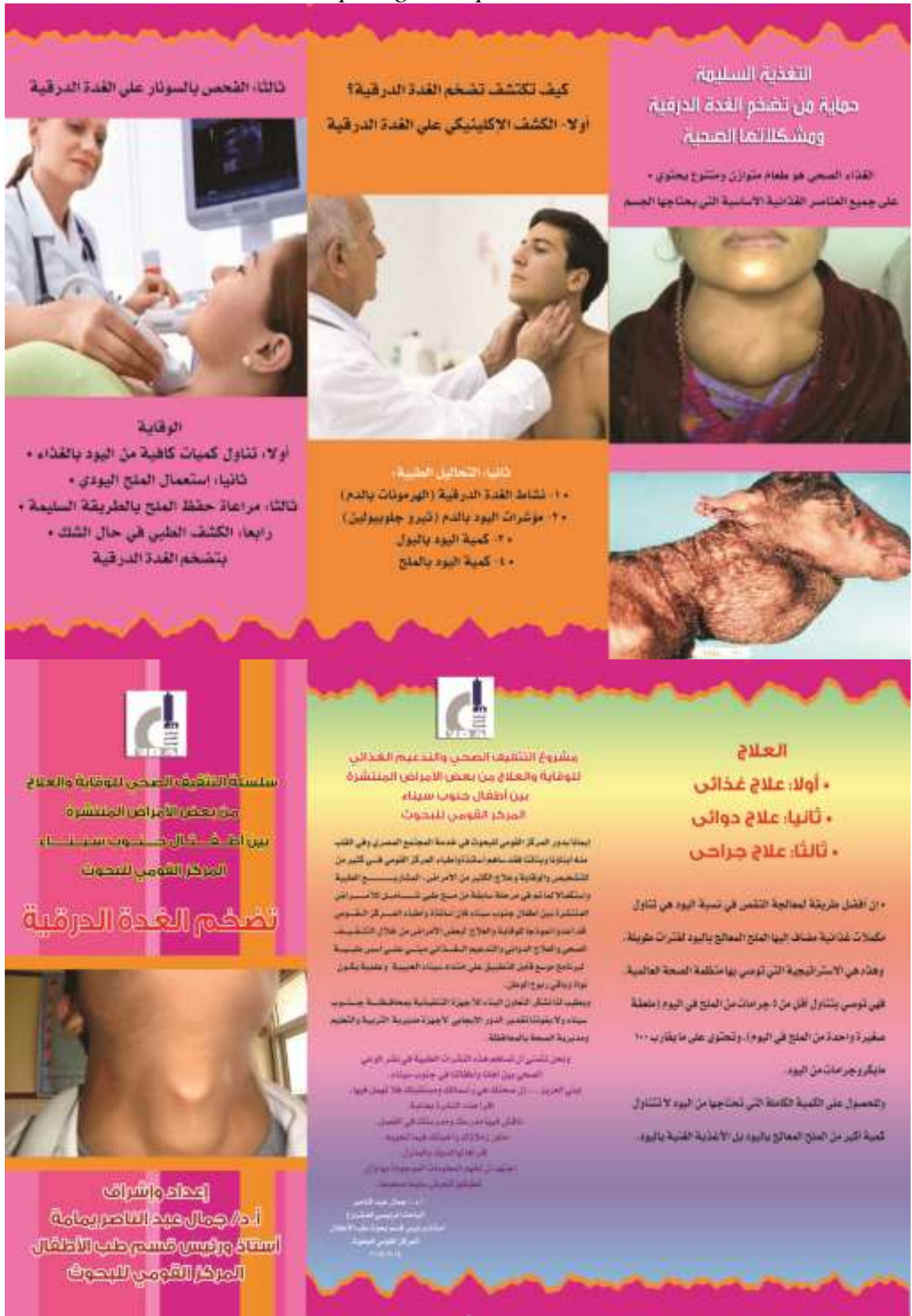


Annex III. Pediculosis and scabies - Mode if infection, clinical presentation, prevention and treatment

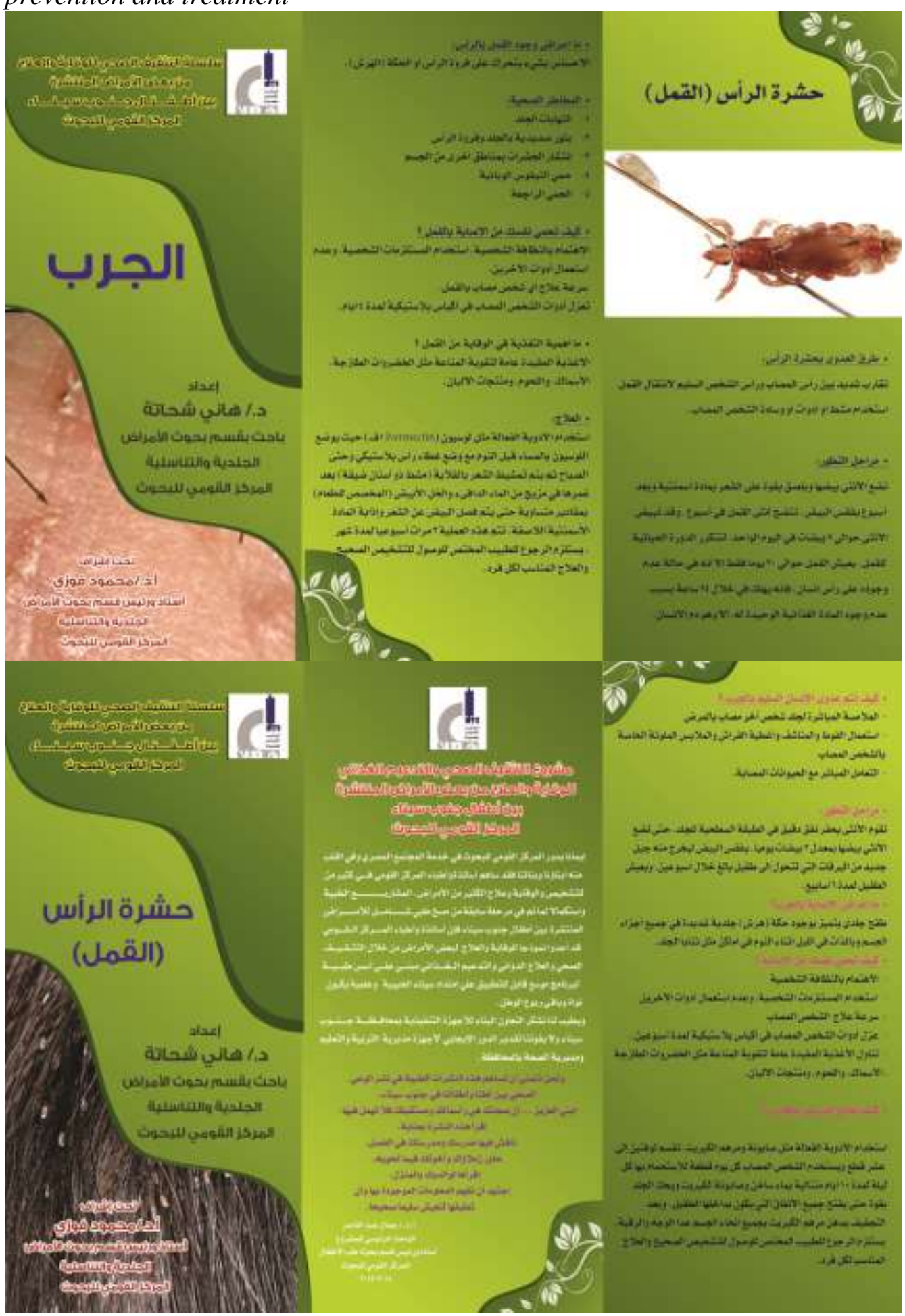


Annex IV. Seborrheic dermatitis, Warts and xerosis - Mode of infection, clinical presentation, prevention and treatment
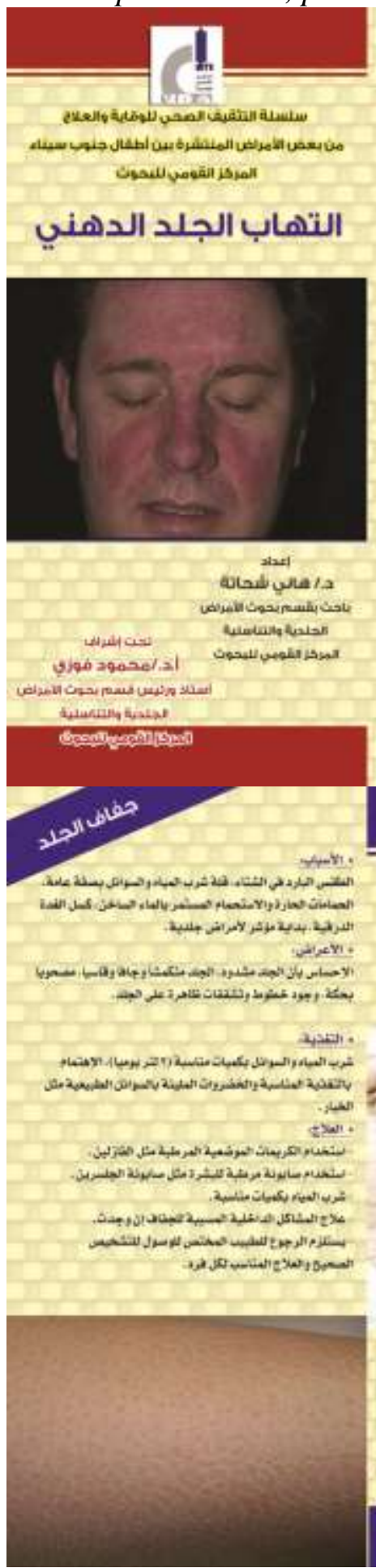

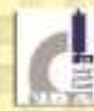

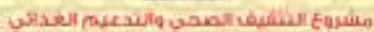

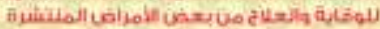

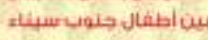

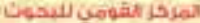

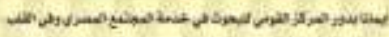
年

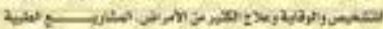

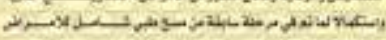

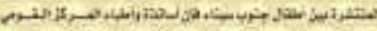

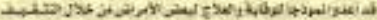

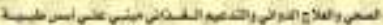

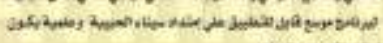
ingtrivityay

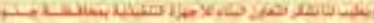

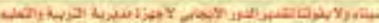

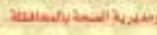

nq

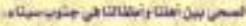

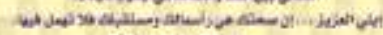

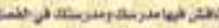
ئ ajoryopexwis

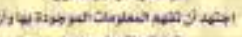

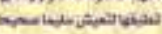

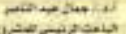

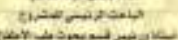
andion

Mis.il

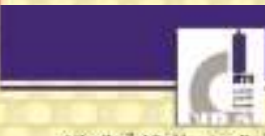

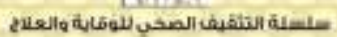

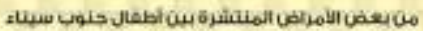

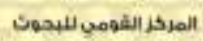

جفاف الجلد

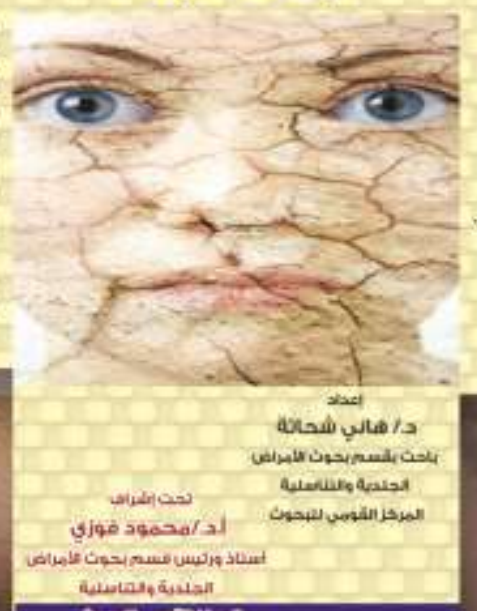

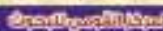

\section{السنس}

this

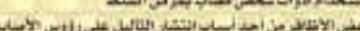

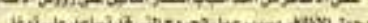
पnis this

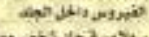

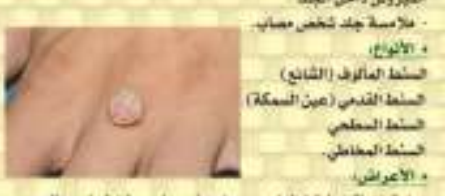

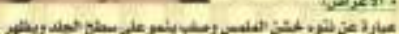

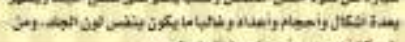

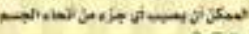
yasp.

20 ئ

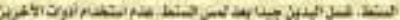
然

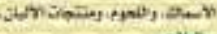

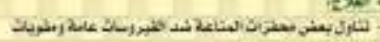

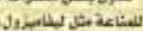

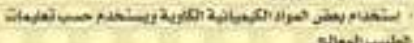
Sllow

.

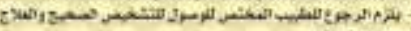
The

\section{whallatall wint}

تصن

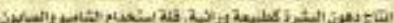

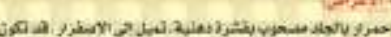

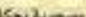
Sol

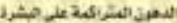

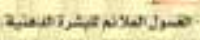

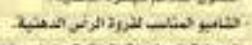

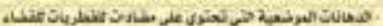

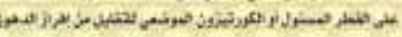

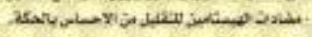

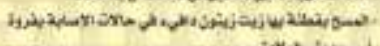
أن :

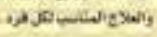

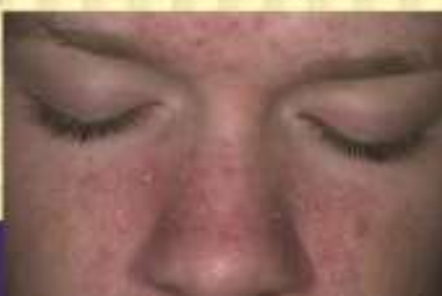


Annex V. Pitriasis alba and acne vulgaris - Etiology, clinical presentation, prevention and treatment

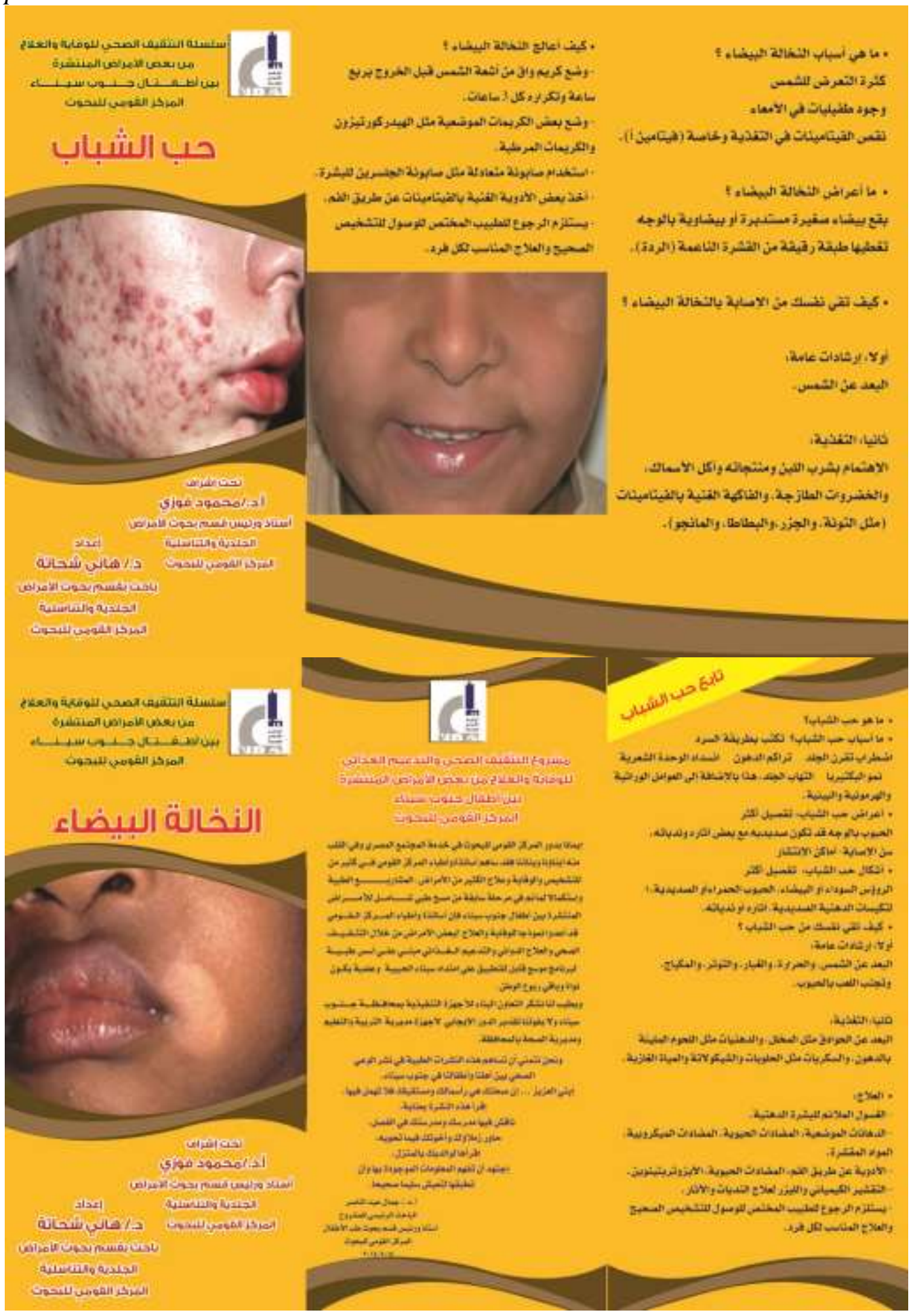




\section{References}

Abdelkader M (2005) The South Sinai Governorate Book: Egyptian Governorates Series. Cairo, Egypt: Centre for Political and Strategic Studies.

Bulliyya G, Dwibedi B, Mallick G, Sethy PG, Kar SK (2008) Determination of iodine nutrition and community knowledge regarding iodine deficiency disorders in selected tribal blocks of Orissa, India. Journal of Pediatrics Endocrinololy and Metabolism 21(1): 79-87.

Can G, Okten A, Green J (2001) The role of local mass media in promoting the consumption of iodized table salt. Health Education Research 16(5): 603-607.

Danin A (1983) Desert Vegetation of Israel and Sinai. Jerusalem: Cana Publishing House.

El Sayed NA, Ismail HM, Hussein MA, Kamel AR (1995) Assessment of the prevalence of iodine deficiency disorders among primary school children in Cairo. East Mediterrean Health Journal 1: 55-63.

Griffiths CEM, Camp RDR, Barker JNWN (2004) Psoriasis. In T Burns, S Breathnach, N Cox, C Griffiths (Eds.), Rook's Textbook of Dermatology, 7th edn. Oxford: Blackwell Science, pp. 300-345.

Hawk JLM, Young AR, Ferguson J (2004) Cutaneous photobiology. In T Burns, S Breathnach, N Cox, C Griffiths (Eds.), Rook's Textbook of Dermatology, 7th edn. Oxford: Blackwell Science, pp. 501-512.

Hetzel BS (1989) The history of goiter and cretinism. In BS Hetzel (Eds.), The story of iodine deficiency: an international challenge in nutrition. Oxford University Press, New York, pp. 3-20.

Iwaco Egypt, Seam Programme (2003) Water Resources Assessment for the South Sinai Environmental Profile and Action Plan, Phase I: Overview of Water Resources in South Sinai. Draft Final Report, October 2003.

Jukić T, Dabelić N, Rogan SA, Nõthig-Hus D, Lukinac L, Ljubicić M, et al. (2008) The story of the Croatian village of Rude after fifty years of compulsory salt iodination in Croatia. Collegium Antropologicum 32: 1251-1254.

Kim BK, Jeong JY, Seok KH, Lee AS, Oak CH, Kim GC, et al. (2014) Current iodine nutrition status and awareness of iodine deficiency in tuguegarao, Philippines. International Journal of Endocrinology. doi: 10.1155/2014/210528.

LaMorte W (2016) Evaluating Screening Programs. SPH, Boston University. Retrieved from https://bit.ly/2Ljszof.

Lowe N, Westaway E, Munir A, Tahir S, Dykes F, Lhussier M, et al. (2015) Increasing Awareness and Use of Iodised Salt in a Marginalised Community Setting in NorthWest Pakistan. Nutrients 7(11): 9672-9682.

Mansour E, Abdel Raouf RK, El-Nekhily I, Ahmed A, Moharam N (2001) Iodine deficiency among school children in Qualiobia and Demietta Governorates. Journal of Antimicrobial Chemotherapy 12: 683-701.

Ohkubo S, Sullivan TM, Harlan SV, Timmons BT, Strachan M (2013) Guide to monitoring and evaluating knowledge management in global health programs. Baltimore, MD: Center for Communication Programs, Johns Hopkins Bloomberg School of Public Health. Retrieved from https://bit.ly/2x8Omge.

Rajapkse BDM (2008) Introduction to health education. Retrieved from https://bit.ly/ 2s4TywF.

SEAM (2004) South Sinai Environmental Action Plan: South Sinai Demographics and Population Projections. Retrieved from https://bit.ly/2IGXk5z.

WHO/ICCIDD (1997) Recommended normative values for thyroid volume in children aged 6-15 years. Bulletin of World Health Organization 75: 95-97. 
WHO-UNICEF-ICCIDD (2003) Global Iodine nutrition IDD Newsletter. 19: 24-35.

Yamamah GA, Kamel AF, Abd-El Dayem S, Hussein AS, Salama H (2013) Thyroid volumes and iodine status in Egyptian South Sinai schoolchildren. Archives of Medical Science 9(3): 548-554.

Yamamah GA, Emam HM, Abdelhamid MF, Elsaie ML, Shehata H, Farid T, et al. (2012) Epidemiologic study of dermatologic disorders among children in South Sinai, Egypt. International Journal of Dermatology 51: 1180-1185.

Yamamah GH, Hassanien MH (1997) Prevalence of goiter among school children of the New Valley: The value of urinary iodine in diagnosis and prognosis. Journal of Arab Child 8: 553-563.

Zimmermann MB, Hess SY, Molinari L, De Benoist B, Delange F, Braverman LE, et al. (2004) New reference values for thyroid volume by ultrasound in iodine sufficient schoolchildren: a World Health Organization/Nutrition for Health and Development Iodine Deficiency Study Group Report. American Journal of Clinical Nutrition 79: 231-237. 